\title{
Effects of Particle Sizes on the Properties of Binderless Boards Made from Rattan Furniture Waste
}

\author{
Zuraida Ahmad*, Maisarah Tajuddin, Md Abd Maleque and Zahurin Halim \\ Department of Manufacturing and Materials Engineering, Kuliyyah of \\ Engineering, International Islamic University Malaysia (IIUM), P.O. Box 10, \\ 50728 Kuala Lumpur, Malaysia
}

*Corresponding author: zuraidaa@iium.edu.my

Published online: 30 April 2019

To cite this article: Zuraida Ahmad, Maisarah Tajuddin, Md Abd Maleque and Zahurin Halim (2019). Effects of particle sizes on the properties of binderless boards made from rattan furniture waste. Journal of Engineering Science, 15, 49-61, https://doi.org/10.21315/ jes2019.15.5.

To link to this article: https://doi.org/10.21315/jes2019.15.5

\begin{abstract}
Rattan furniture had produced high amount of wastes with different particle sizes that could be used in manufacturing binderless boards $(B B)$, which were the boards that reduced or excluded the use of synthetic resins in board production. Therefore this research is executed to study the effect of particle sizes of rattan furniture waste (RFW) on the properties of BB produced via hot-pressing technique. The pressing parameters is fixed at the temperature of $180^{\circ} \mathrm{C}$, pressing pressure of $1.5 \mathrm{MPa}$ and holding time of $5 \mathrm{~min}$ using different particle sizes of 50, 100, 250 and $500 \mu \mathrm{m}$ and denoted as BB50, BB100, $B B 250$ and BB500 respectively. All the BB samples underwent bending, internal bonding, thickness swelling, water absorption and morphological testing. The BB50 had the best properties with modulus of rupture (MOR) of $24.3 \mathrm{MPa}$, internal bonding (IB) of $0.35 \mathrm{MPa}$, thickness swelling (TS) of $20.2 \%$ and water absorption (WA) of $48.2 \%$. scanning electron microscope (SEM) morphology shows the compact and tight bonding among fibres for BB50. In contradict, the BB500 had the lowest values due to weak bonding and occurrence of voids inside the BB. Physical consolidation among the fibres inside BB and degradation of chemical components inside $R F W$ were the anticipated self-bonding mechanism that occurred during the production of BB via this hot-pressing process.
\end{abstract}

Keywords: binderless, rattan, particle sizes, self-bonded, cross-linking, physical consolidation, chemical degradation, morphology 


\section{INTRODUCTION}

The production of rattan furniture for house decoration in replacing wood, had become one of the most important non-timber forest products with large worldwide market of exporting values of RM3.3 million in 2016. ${ }^{1}$ The great versatility of rattan such as its durability, elasticity, light-weight, shiny and flexibility can be used in various applications, for instance furniture industries, construction materials, household articles, tool handles, lifting heavy items and bridge construction. The furniture industry of rattan furniture, however, creates high amount of waste that come from debarking, skinning, coring and cutting processes. ${ }^{2}$ The high wastage produced during the process of making rattan furniture product was contributed by rattan poles that also cost as much as $10 \%$ of average price of rattan poles. ${ }^{2,3}$ These rattan wastes need to be converted into something that might be useful to human being, as it is closely related and can be used in the same industry, as furniture or building components.

The existing commercial boards generally made of woody and non-woody based materials, which are mixed with synthetic resins such as urea-formaldehyde (UF) or phenol-formaldehyde (PF) during the manufacturing process to increase the boards' strength, quality and reliability. This synthetic resin could also bring side effects on human's health such as cancer and irritation of eyes, nose and throat; and lead to environmental pollution. ${ }^{4}$ The possible way to overcome these problems is by reducing or excluding the use of synthetic resins in board manufacturing, as self-bonded or binderless boards. The development of binderless boards (BB) using various kinds of renewable raw materials have been introduced since early 1980s, which promises brighter prospect because of its good qualities which found to be environmental-friendly, renewable, recyclable and economical..$^{5-8}$

Hot-pressing process is widely recognised in fabrication process of BB, owing to its easiness and simplicity of manufacturing method compared to other methods. ${ }^{5,9,10}$ This method did not entail extraordinary skills, yet the fundamental knowledge on the process works were necessity. The elementary principle of hot-pressing was the application of adequate heat and pressure within sufficient time onto the fibres throughout the entire material during pressing where few other factors had given effects on properties of BB produced. ${ }^{7,8,10,11}$ The utmost important parameter for this hot-pressing process were pressing temperature, with the regular reporting optimal temperature used that was $180^{\circ} \mathrm{C}-200^{\circ} \mathrm{C} .^{9,12-14}$ Thermal analysis on the material used gave ideas and guidelines, especially on melting point and softening temperature of fibres; to evade severe fibre burned and damaged which reduced the fibre properties. In general, fibres started losing free water at temperature below $50^{\circ} \mathrm{C}$, followed by chemical transformation occurred 
at temperature of $180^{\circ} \mathrm{C}-250^{\circ} \mathrm{C}$, and finally the formation of carbonisation process with pyrolysis products at temperature above $250^{\circ} \mathrm{C}$.

The particle size and geometry ominously influence the properties of BB in terms of bonding quality among particles, compared to mechanical strength properties of the fibres themselves. Previous studies ${ }^{15,16}$ had shown that smaller particles improved the qualities of the BB with a superior internal bond strength as the smaller particles were more compressed with fewer overlapping areas, producing uniform homogeneous cells, which had lower voids. Interestingly, this leads to better dimensional stability and gives a smoother surface for BB compared to larger particles. ${ }^{16}$ Hence, the optimal pressing parameters must be recognised to obtain optimum properties of BB. This research aims to study the effects of particle sizes onto the properties of manufactured BB made from rattan furniture waste (RFW).

\section{EXPERIMENTAL PROCEDURES}

RFW were attained from manufacturing process of rattan furniture, provided by Rinaat Cane Sdn. Bhd. in Perak, Malaysia. The wastes came in mixed components forms, which were cut and blended using rotor mill that produced particles with size ranges of 50 to $500 \mu \mathrm{m}$. These RFW, afterward, were sieved using electronic siever with mesh screen sizes of 50, 100, 250 and $500 \mu \mathrm{m}$ and were dried in the oven at $40^{\circ} \mathrm{C}$ for $48 \mathrm{~h}$. Subsequently, $80 \mathrm{~g}$ of dried RFW was manually hand-formed into mould mat with the size of $11 \times 11 \mathrm{~cm}$. The mat was eventually hot-press at pressing temperature of $180^{\circ} \mathrm{C}$ and pressing pressure of $1.5 \mathrm{MPa}$ for 5 min of pressing time, as displayed in Table 1, to produce BB without using any binders. The schematic diagram of hot-pressing process for manufacturing binderless board made from RFW is elucidates in Figure 1.

Table 1: Pressing parameters used in manufacturing BB.

\begin{tabular}{lcccc}
\hline Samples name & $\begin{array}{c}\text { Particle size } \\
(\mu \mathrm{m})\end{array}$ & $\begin{array}{c}\text { Pressing temperature } \\
\left({ }^{\circ} \mathrm{C}\right)\end{array}$ & $\begin{array}{c}\text { Pressing pressure } \\
(\mathrm{MPa})\end{array}$ & $\begin{array}{c}\text { Pressing time } \\
(\mathrm{min})\end{array}$ \\
\hline BB50 & 50 & 180 & 1.5 & 5 \\
BB100 & 100 & 180 & 1.5 & 5 \\
BB250 & 250 & 180 & 1.5 & 5 \\
BB500 & 500 & 180 & 1.5 & 5 \\
\hline
\end{tabular}




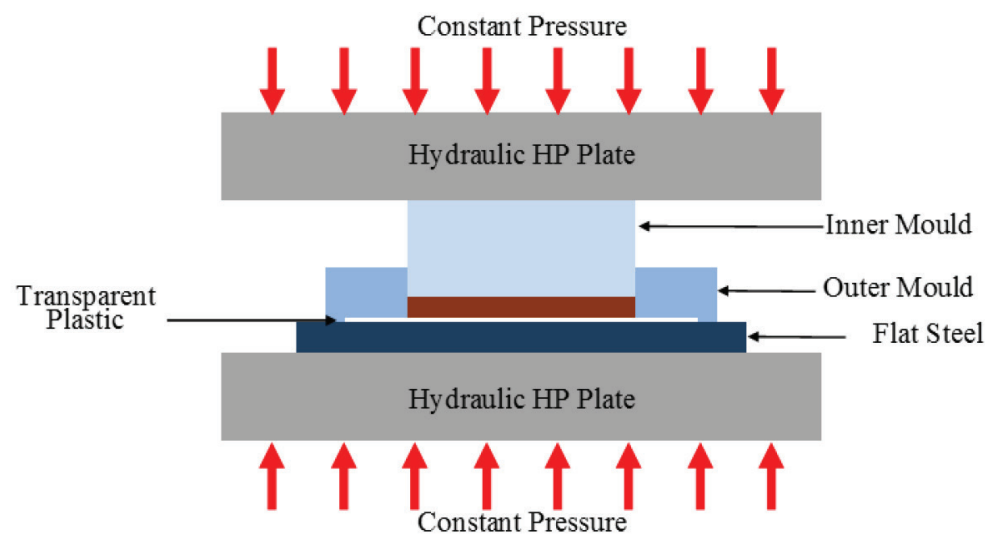

Figure 1: Schematic diagram of hot-pressing process in manufacturing BB.

The test samples of manufactured BB were prepared in accordance to Japanese Industrial Standard (JIS) for Particleboards, ${ }^{17}$ for bending for modulus of rupture (MOR), internal bonding (IB), dimensional stability and morphology tests. The bending and IB test were conducted using Shimadzu Precision Universal Testing Machine Autograph (model AGS-X Series), with three samples for each conditions were prepared and conditioned as required by the boards' standard. A loading speed of $10 \mathrm{~mm} / \mathrm{min}$ was applied onto the middle part of bending samples of $110 \times 50 \times 5 \mathrm{~mm}$ size. While, the IB samples of $50 \times 50 \mathrm{~mm}$ size were placed in between two metallic grips of clamping devices, where $2 \mathrm{~mm} / \mathrm{min}$ of tension loading speed was applied progressively until the sample break. Both MOR and IB values were calculated. Thickness swelling (TS) and water absorption (WA) were performed under dimensional stability tests, where three $50 \times 50 \mathrm{~mm}$ samples of each condition underwent these tests. The samples were fully immersed in the water of $20 \pm 1^{\circ} \mathrm{C}$ horizontally for $24 \mathrm{~h}$, and were taken out from water after that. The percentage of TS and WA were calculated and recorded.

Morphological analysis were executed using scanning electron microscope (SEM) (model Hitachi SU1510), which operating at $15 \mathrm{kV}$ at 250× magnification. The samples were cut into one cubic centimeter size, and blow-dried using small hand-dryer to remove dusts on the surface of sample during cutting process. The samples then were mounted on the aluminum holders using double-sided electrically conductive carbon adhesion tape and coated with a thin layer of gold to improve conductivity in order to avoid sample charging as well as to maintain the quality of images. The samples also were examined under optical microscope (OM) (model Olympus Optical Microscope BX 41M), at magnification of 100×. 


\section{RESULTS AND DISCUSSION}

The physical appearance of $\mathrm{BB}$ produced from various particle size of 50 , 100, 250 and $500 \mu \mathrm{m}$ are shown in Figure 2. The surfaces of manufactured BB had smooth surfaces and generated peculiar smells which were believed as indication for chemical components modification of fibres. ${ }^{8,18}$ The BB50 was relatively solid compared to other BB.

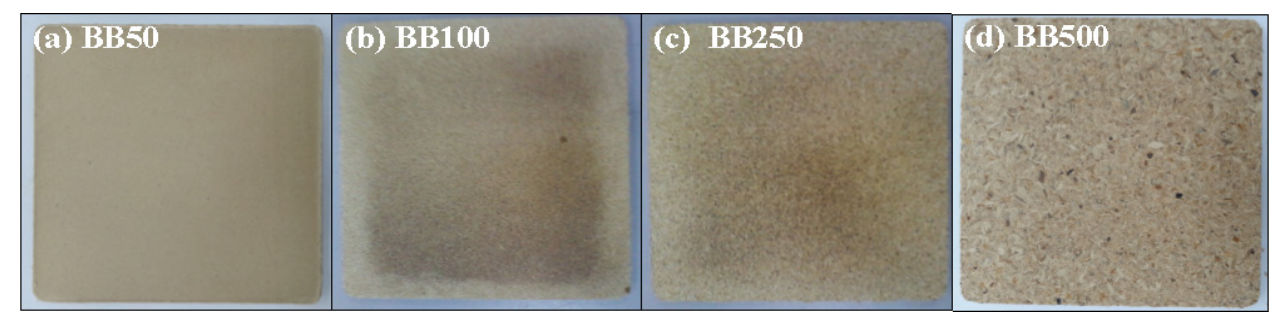

Figure 2: BB made from RFW in particle sizes of (a) 50, (b) 100, (c) 250 and (d) $500 \mu \mathrm{m}$.

\subsection{Mechanical and Internal Bonding Properties of Manufactured BB}

Figure 3 shows the MOR and IB values, where both graphs reveal the similar pattern with reduction in strength values of the produced BB. The BB50 displayed the highest MOR and IB values of 24.3 and $0.35 \mathrm{MPa}$, respectively. On contrary, the BB500 exhibited the lowest values of 8.9 and $0.18 \mathrm{MPa}$ for MOR and IB, which estimated $50 \%$ to $60 \%$ lower compared than BB50. Similar results were gained from former researches, ${ }^{6,19}$ which the reduction of mechanical strength was due to the less attachments between fibre bonding. Moreover, the pressing pressure used in this study was fixed and considered lower relatively to other studies. ${ }^{7,12}$ The strength of internal bond principally depended upon the internal bonding among fibres, instigated by chemical bonding from the reaction of heat applied onto chemical components inside the RFW fibres. This was agreeable with a study conducted by previous researches ${ }^{20,21}$ that specified the focus on high internal bonding yielded better stability due to good contact between particles and helped to reduce moisture penetration into BB. The BB50 and BB100 had met the minimum requirement of board standards for 13.0 MPa of MOR values; meanwhile for the IB values, all the manufactured $\mathrm{BB}$ met the minimum requirement of board standard except for BB500. ${ }^{17}$ The smaller the size of fibres used, positively increased the bonding of fibres and the properties of manufactured $\mathrm{BB}$. 


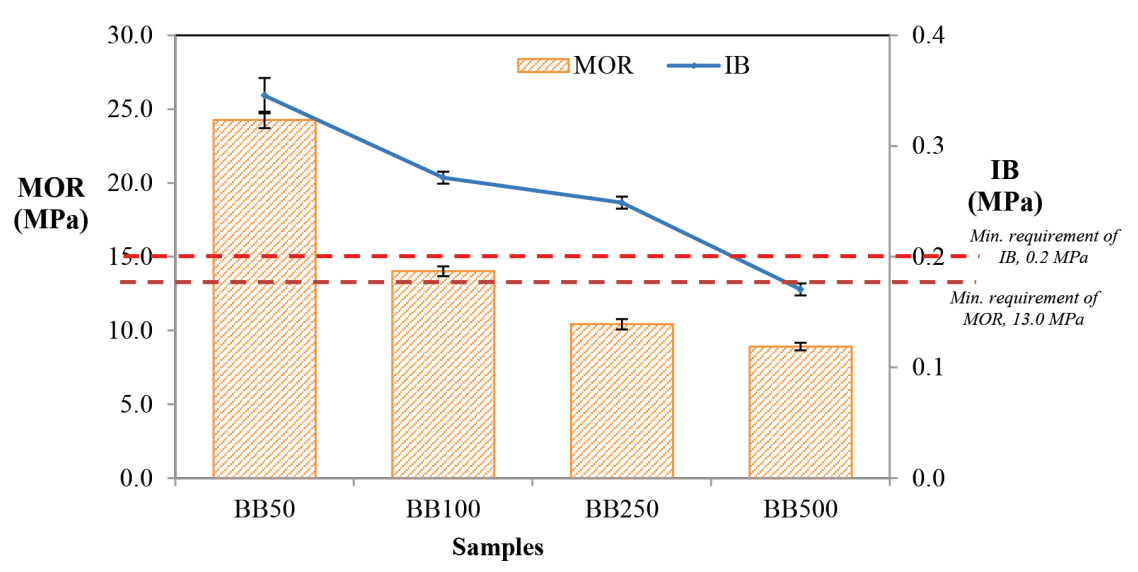

Figure 3: MOR and IB graphs for manufactured BB made from different particle sizes.

\subsection{Dimensional Stability Properties of Manufactured BB}

The graph of dimensional stability of manufactured BB consisted of thickness swelling (TS) and water absorption (WA) values are demonstrated in Figure 4. BB50 had TS value of $20.2 \%$, and BB100 had TS value of $57.8 \%$ which is drastically increased up to $56.6 \%$. Small particles helped to compact fibres, absorbed less water and prevented water from penetrating into boards and swelled less in thickness of the board. ${ }^{19}$ The voids between fibres allowed the water to penetrate inside the BB, thus increased the TS values. ${ }^{9}$ The TS values for BB250 and BB500 samples could not be measured as they swelled cracked into small pieces after taken out from water. There is none of manufactured BB had TS value below $12 \%$, which they did not met the board standard requirement. ${ }^{17}$ Due to this, the manufactured BB were only suitable for general purpose (Type P1) or interior fitment in dry condition (Type P2) particleboard. The similar pattern is shown by WA values, where WA values were relatively high, owing to the porous character that absorbed more water due to big particle size such as BB250 and BB500. This is proven due to the capillary action that induced an uptake of water that caused swelling to occur which made the disappearance of van der Waal interaction between lignin rich fibre surfaces in which resulted in decreasing the inter-fibre bonding area. ${ }^{22}$ 


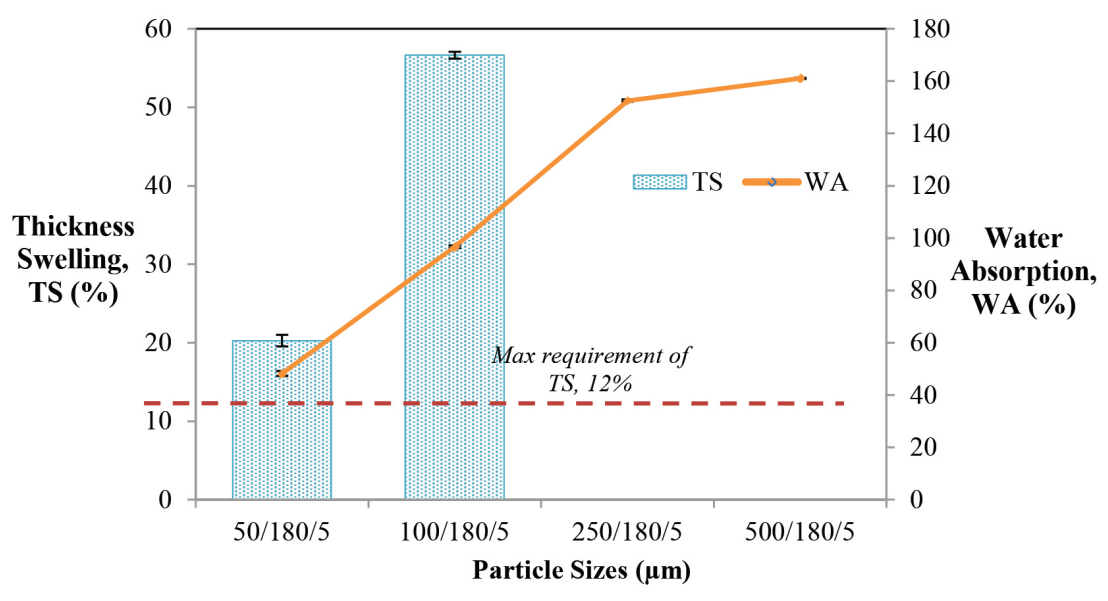

Figure 4: Dimensional stability graph of manufactured BB made from different particle sizes of RFW.

\subsection{Morphological Analysis of Manufactured Rattan Waste Binderless Board (RWBB)}

Figure 5 illustrates the surface morphologies of manufactured BB under SEM with 250× magnification. The fibres in Figure 5(a) from BB50 sample were compactly packed together and designated the good bonding among the fibres. The boards were hardly broken which were proven through the mechanical tests as described above. Some of impurities could be seen in Figure 5(b) that might affect properties of BB100 sample. In the Figures 5(c) and 5(d) for BB250 and BB500 samples respectively, there were obvious voids and gaps among fibres as the particle size increased. The fibres clearly did not bind neatly resulted in very weak bonding proven from the low values of strength, internal bonding and low dimensional stability of the manufactured BB.

Figure 6 demonstrates the surface of manufactured BB captured through $\mathrm{OM}$ at magnification of $100 \times$. The sample in Figure 6(a) had a clear, smooth, plastic-like, and shiny surface compared to other samples. The small fine particle sizes abridged fibres to cling together and this had made it easy to create compacted fibre network over large surface area, thus, producing good properties of binderless board. ${ }^{14,23}$ The occurrence of void could be seen particularly in manufactured BB with bigger particle size such as in Figure 6(d). Hence, the use of small particles still had advantages in terms of having less void spaces compared to bigger particles 
making them offering more surface areas bonded together as particle were closer to each other.

\subsection{Self-bonding Mechanisms of Manufactured BB}

Morphological analysis in Figures 5 and 6 proved the two self-bonding mechanism transpired inside the manufactured BB under hot-press process where the heat and pressure applied onto the fibres. Physical consolidation amongst fibres occurred when the pressure applied until there was no air space between fibres, thus ensuring the fibres deform sufficiently to get intimate fibre-fibre contact and deterred macroscopic porosity from vapour evacuation..$^{14,24,25}$ The maximum deformation occurred during rubbery state of rattan fibres contributed to the largest contact areas between fibres. It is an additional advantage when the material had special attributes such as cell wall deformation ability. ${ }^{4,25}$ The pressing temperature had to be higher than glass transition temperature $\left(T_{g}\right)$ of rattan fibres. Fibre surfaces were important as it served as interphase or level of contacts between fibres to be bonded which included surface geometry, surface entanglement on a macro or molecular-scales. ${ }^{26}$ This is because, any fibre surface irregularity, non-uniformity of fibre arrangements, large defects and unsuitable conditions could cause little contact of proximity (within few $\mu \mathrm{m}$ ) between fibre elements. ${ }^{14,26}$ Big pores with high ratio of lumen dimension to cell wall dimension and such a shape renders of parenchyma cells were more susceptible to deformation when being pressed leads to better intercellular and interparticle bonding. ${ }^{18}$ Higher pressure needed to be applied on the manufactured BB made from bigger particle sizes to ensure the fibres bend and to be attached to each other, so they interlocked amongst them. It was also important for the vascular bundles to be compactly packed, so there was no void occurred and improved the properties of manufactured BB. 

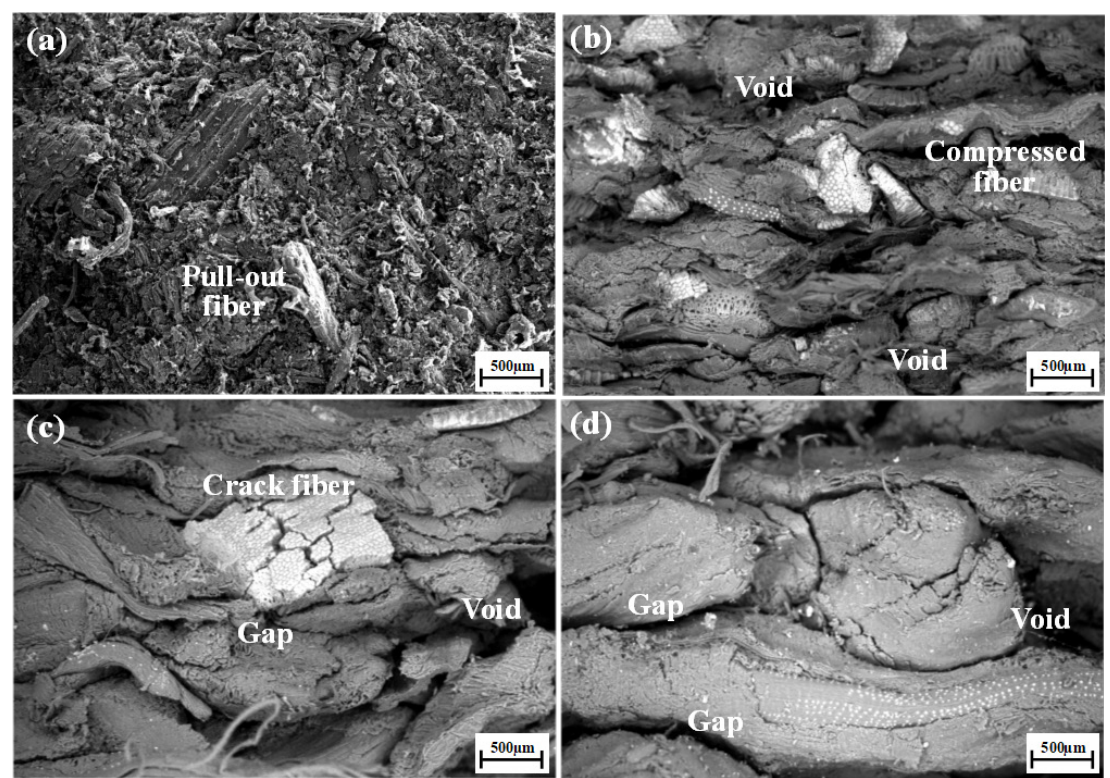

Figure 5: SEM micrographs at 250× magnification of manufactured BB samples named as (a) BB50, (b) BB100, (c) BB250 and (d) BB500.
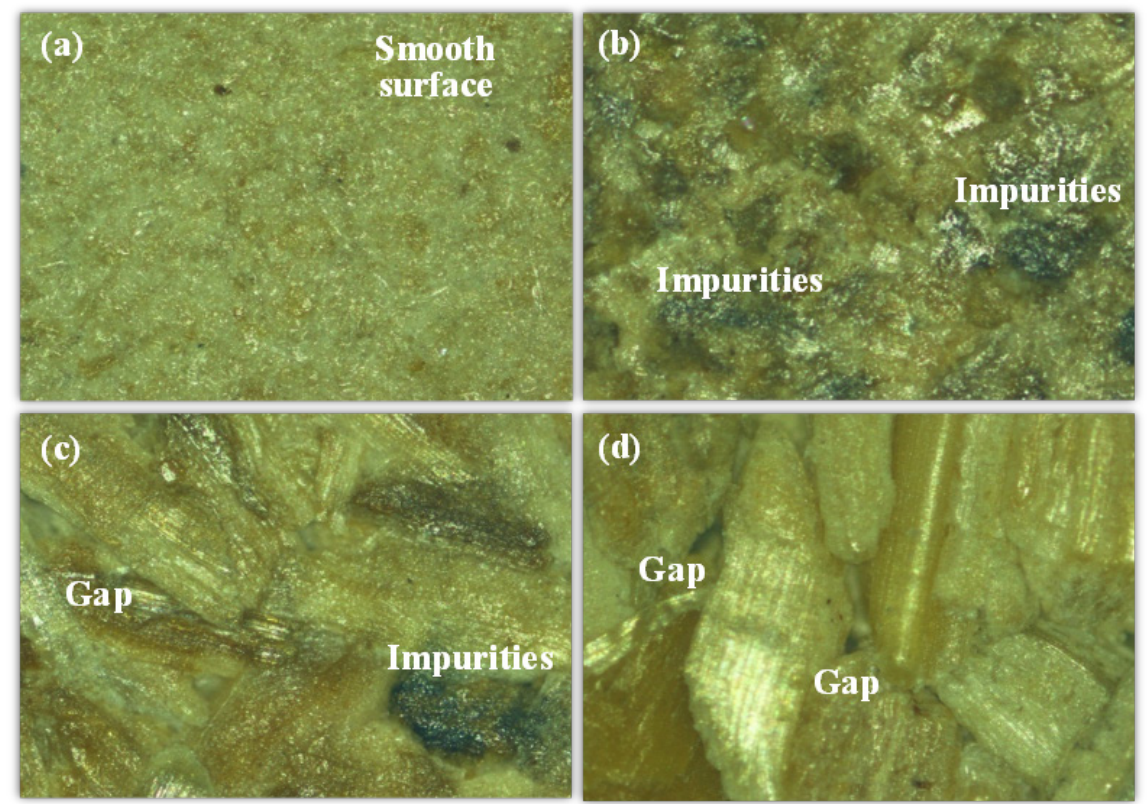

Figure 6: Exterior surface views through $\mathrm{OM}$ at $100 \times$ magnification of manufactured $\mathrm{BB}$ samples named as (a) BB50, (b) BB100, (c) BB250 and (d) BB500. 
On the other hand, a peculiar smell during hot-pressing was believed to be the indication that chemical components inside the BB were modified, through degradation process and hydrolysis reaction; that usually happened at higher temperature generally about $180^{\circ} \mathrm{C} .{ }^{9,14,22}$ The degradation process propagated up to heteropolysaccharide and lignin components, contributed to the formation and retention of free radical. Free radical led to surges of fibre reactivity that triggered cross-linking formation of covalent bonds between lignin-lignin and lignin-heteropolysaccharide: the strongest bond that could not be reformed, ${ }^{27}$ that facilitated self-bonding, improved adhesion and provided good mechanical properties..$^{11,12,24,25}$ Meanwhile, the hydrolysis reaction formed some sugar, acetic and formic acids that hydrolysed hemicellulose. ${ }^{18}$ The reaction caused loss in moisture content resulted in pentoses and hexoses dehydrated through condensation reaction to furfural and hydroxymethyl furfural. ${ }^{9}$ These products of furfural, together with lignin were designed into new components such as lignin-cellulose via hydrogen bond. ${ }^{11}$ Another hydrolysis reaction occurred were the depolymerisation of cellulose in amorphous area which caused the break of cellulose into shorter chains and the polycondensation of lignin at temperature more than $155^{\circ} \mathrm{C}$ with furfural formed. ${ }^{18}$ Thus, this activated lignin-furfural bond to split which exposing it to new functional group and sites that involved in crosslinking of lignin network produced natural adhesives that bind the fibres together., ${ }^{9,22}$

The self-bonding mechanisms are correlated to each other where it might be interdependent with the combination of chemical structures and physical properties of fibres as well as complex association of manufacturing pressing conditions: pressure, temperature, time. ${ }^{9,14}$

\section{CONCLUSIONS}

Hot-pressing process is easy and simple methods that did not require extraordinary skills, yet it still needs the fundamental knowledge on the process works. BB made from RFW was manufactured through hot-pressing process, with best properties from BB50 which were MOR of $24.3 \mathrm{MPa}$, IB of $0.35 \mathrm{MPa}$, TS of $20.3 \%$ and WA $48.2 \%$. BB made from smaller particle size resulted in less void spaces with compact fibres bonding that improved the properties of manufactured $\mathrm{BB}$ compared to bigger particles.

The mechanism of self-bonding that involved were physical consolidation among fibres and modification of chemical components occurred through degradation process and hydrolysis reaction of rattan waste fibres. 


\section{ACKNOWLEDGEMENTS}

The authors would like to acknowledge the financial support provided by Ministry of Higher Education (Malaysia) for the sponsorship scheme of Grant No. FRGS15-206-0447 and also facilities conveyed in International Islamic University Malaysia (IIUM).

\section{REFERENCES}

1. Malaysian Furniture Council (2017). Malaysian Furniture News, Issue 5. Retrieved from http://www.mfc.my/images/stories/pdf/MFC_5thIssue. pdf on 13 August 2017.

2. Olorunnisola, A. O. (2004). Briquetting of rattan furniture waste. J. Bamboo Rattan, 3(2), 139-149, https://doi.org/10.1163/156915904774 195133.

3. Food and Agriculture Organization of the United Nations (n.d.). Rattan furniture unit, Malaysia. Retrieved from http://teca.fao.org/read/3883 on 15 December 2015.

4. Charoenvai, S. (2013). New insulating material: Binderless particleboard from durian peel. In S. -Y. Chang, S. K. Al Bahar \& J. Zhao (eds.), Advances in civil engineering and building materials. London: Taylor and Francis, 119-123.

5. Okuda, N. \& Sato, M. (2004). Manufacture and mechanical properties of binderless boards from kenaf core. J. Wood Sci., 50(1), 53-61, https://doi. org/10.1007/s10086-003-0528-8.

6. Baskaran, M., Azmi, N. A. C. H., Hashim, R. \& Sulaiman, O. (2017). Properties of binderless particleboard and particleboard with addition of urea formaldehyde made from oil palm rattan waste. J. Phys. Sci., 28(3), 151-159, https://doi.org/10.21315/jps2017.28.3.10.

7. Saadaoui, N., Rouilly, A., Fares, K. \& Rigal, L. (2013). Characterization of date palm lignocellulosic by-products and self-bonded composite materials obtained thereof. Mater. Des., 50, 302-308, https://doi.org/10.1016/j. matdes.2013.03.011.

8. Hidayat, H., Keijers, E. R. P., Prijanto, U., van Dam, J. E. G. \& Heeres, H. J. (2014). Preparation and properties of binderless boards from Jatropha curcas L. seed cake. Ind. Crops Prod., 52, 245-254, https://doi. org/10.1016/j.indcrop.2013.10.024.

9. Zhang, D., Zhang, A. \& Xue, L. (2015). A review of preparation of binderless fibreboardsand its self-bonding mechanism. Wood Sci. Technol., 49(4), 661-679, https://doi.org/10.1007/s00226-015-0728-6. 
10. Pesenti, H., Torres, M., Oliveira, P., Gacitua, W. \& Leoni, M. (2017). Exploring Ulex europaeus to produce nontoxic binderless fibreboard. BioRes., 12(2), 2660-2672, https://doi.org/10.15376/ biores.12.2.2660-2672.

11. Kurniati, M., Fahma, F., Kartika, I. A., Sunarti, T. C., Syamsu, K., Hermawan, D., Saito, Y. \& Sato, M. (2015). Binderless particleboard from castor seed cake: Effect of pressing temperature on physical and mechanical properties. Asian J. Agric. Res., 9(4), 180-188, https://doi. org/10.3923/ajar.2015.180.188.

12. Hashim, R., Saari N., Lamaming, J., Baskaran, M., Sulaiman, O., Sato, M., Hiziroglu, S. \& Sugimoto, T. (2011). Influence of press temperature on the properties of binderless particleboard made from oil palm trunk. Mat. Des., 32(5), 2520-2525, https://doi.org/10.1016/j.matdes.2011.01.053.

13. Mancera, C., Ferrando, F. \& Salvado, J. (2008). Cynara cardunculus as raw material for the production of binderless fibreboards: Optimization of pretreatment and pressing conditions. J. Wood Chem. Technol., 28(3), 207-226, https://doi.org/10.1080/02773810802347024.

14. Pintiaux, T., Viet, D., Vandenbossche, V., Rigal, L. \& Rouilly, A. (2015). Binderless materials obtained by thermos-compressive processing of lignocellulosic fibres: A comprehensive review. BioRes., 10(1), 19151963.

15. Zuraida, A., Insyirah, Y., Maisarah, T. \& Zahurin, H. (2017). Influence of fibre treatment on dimensional stabilities of rattan waste composite boards. IOP Conf. Ser.: Mater. Sci. Eng., 290, 012029, https://doi. org/10.1088/1757-899x/290/1/012029.

16. Hashim, R., Saari, N., Sulaiman, O., Sugimoto, T., Hiziroglu, S., Sato, M. \& Tanaka, R. (2010). Effect of particle geometry on the properties of binderless particleboard manufactured from oil palm trunk. Mat. Des., 31, 4251-4257, https://doi.org/10.1016/j.matdes.2010.04.012.

17. Japanese Standards Association (2003). Particleboards. JIS A 5908: 2003, Japanese Standards Association.

18. Fahmy, T. Y. A. \& Mobarak, F. (2013). Advanced binderless board-like green nanocomposites from undebarked cotton stalks and mechanism of self-bonding. Cellulose, 20(3), 1453-1457, https://doi.org/10.1007/ s10570-013-9911-9.

19. Ferrandez-Garcia, C. C., Garcia-Ortuno, T., Ferrandez-Garcia, M. T., Ferrandez-Villena, M. \& Ferrandez-Garcia, C. E. (2017). Fire-resistance, physical, and mechanical characterization of binderless rice straw particleboards. BioRes., 12(4), 8539-8549, https://doi.org/10.15376/ biores.12.3.6698-6712. 
20. Boon, J. G., Hashim, R., Sulaiman, O., Hiziroglu, S., Sugimoto, T. \& Sato, M. (2013). Influence of processing parameters on some properties of oil palm trunk binderless particleboard. Eur. J. Wood Wood Prod., 71(5), 583589, https://doi.org/10.1007/s00107-013-0712-5.

21. Marashdeh, M. W., Hashim, R., Tajuddin, A. A., Bauk, S. \& Sulaiman, O. (2011). Effect of particle size on the characterization of binderless particleboard made from Rhizophora Spp. mangrove wood for use as phantom material. BioRes., 6(4), 4028-4044.

22. Lamaming, J., Sulaiman, O., Sugimoto, T., Hashim, R., Said, N. \& Sato, M. (2013). Influence of chemical components of oil palm on properties of binderless particleboard. BioRes., 8(3), 3358-3371, https://doi. org/10.15376/biores.8.3.3358-3371.

23. Panyakaew, S. \& Fotios, S. (2011). New thermal insulation boards made from coconut husk and bagasse. Energy Build., 43(7), 1732-1739, https:// doi.org/10.1016/j.enbuild.2011.03.015.

24. Hashim, R., Wan Nadhari, W. N. A. \& Sulaiman, O. (2016). Green binderless board from oil palm biomass. In M. I. Ahmad, M. Ismail \& S. Riffat (eds.), Renewable energy and sustainable technologies for building and environment applications. Basel, Switzerland: Springer Int. Pub. Switzerland, https://doi.org/10.1007/978-3-319-31840-0_11.

25. Bouajila, J., Limare, A., Joly, C. \& Dole, P. (2005). Lignin plasticization to improve binderless fibreboard mechanical properties. Polym. Eng. Sci., 45(6), 809-816, https://doi.org/10.1002/pen.20342.

26. Felby, C., Thygesen, L. G., Sanadi, A. \& Barsberd, S. (2004). Native lignin for bonding of fibre boards: Evaluation of bonding mechanisms in board made from laccase-treated fibres of beech (Fagus sylvatica). Ind. Crops Prod., 20(2), 181-189, https://doi.org/10.1016/j. indcrop.2004.04.020.

27. Alvarez, C., Rojas, O. J., Rojano, B. \& Ganan, P. (2015). Development of self-bonded fibreboards from fibre of leaf plantain: Effect of water and organic extractives removal. BioRes., 10(1), 672-683, https://doi. org/10.15376/biores.10.1.672-683. 